Article

\title{
Demethylation of Wheat Straw Alkali Lignin for Application in Phenol Formaldehyde Adhesives
}

\author{
Yan Song ${ }^{1,2}$, Zhixin Wang ${ }^{1}$, Ning Yan ${ }^{3}$, Rong Zhang ${ }^{1}$ and Jinchun $\mathrm{Li}^{1,2, *}$ \\ 1 Faculty of Materials Science \& Engineering, Changzhou University, Changzhou 213164, China; \\ ysong@cczu.edu.cn (Y.S.); wzx911003@163.com (Z.W.); rzhang@cczu.edu.cn (R.Z.) \\ 2 Jiangsu Collaborative Innovation Center of Photovolatic Science and Engineering, Changzhou University, \\ Changzhou 213164, China \\ 3 Faculty of Forestry, University of Toronto, 33 Willcocks Street, Toronto, ON M5S 3B3, Canada; \\ ning.yan@utoronto.ca \\ * Correspondence: Lijinchun88@163.com; Tel.: +86-519-8633-0095
}

Academic Editor: Antonio Pizzi

Received: 18 April 2016; Accepted: 24 May 2016; Published: 30 May 2016

\begin{abstract}
Lignin is a natural biopolymer with a complex three-dimensional network. It is the second most abundant natural polymer on earth. Commercially, lignin is largely obtained from the waste liquors of pulping and bioethanol productions. In this study, wheat straw alkali lignin (WSAL) was demethylated by using an in-situ generated Lewis acid under an optimized demethylation process. The demethylation process was monitored by a semi-quantitative Fourier Transform Infrared Spectroscopy (FTIR) method. The demethylated wheat straw alkali lignin (D-WSAL) was further characterized by Proton Nuclear Magnetic Resonance ( ${ }^{1} \mathrm{H}$ NMR), Gel Permeation Chromatography (GPC), and titration methods. After the demethylation process, it was found that the relative value of the methoxy group decreased significantly from 0.82 to 0.17 and the phenolic hydroxyl group increased from $5.2 \%$ to $16.0 \%$. Meanwhile, the hydroxyl content increased from $6.6 \%$ to $10.3 \%$. GPC results suggested that the weighted averaged molecular weight of D-WSAL was lower than that of WSAL with a smaller polydispersity index. The D-WSAL was then used to replace $60 \mathrm{wt} \%$ of phenol to prepare lignin-based phenol formaldehyde adhesives (D-LPF). It was found that both the free formaldehyde content and the free phenol content in D-LPF were less than those of the lignin-based phenol formaldehyde adhesives without lignin demethylation (LPF). Gel time of D-LPF was shortened. Furthermore, the wet and dry bonding strengths of lap shear wood samples bonded using D-LPF were higher than those of the samples bonded using LPF. Therefore, D-WSAL has shown good potential for application in phenol formaldehyde adhesives.
\end{abstract}

Keywords: wheat straw alkali lignin; Lewis acid; demethylation; phenol formaldehyde adhesive

\section{Introduction}

Adhesives are key components in the manufacturing of particleboards, wood panels, fiberboards, and plywood. Among various adhesives, the resole phenol formaldehyde (PF) is most commonly used for exterior applications [1,2]. Commercial PF adhesives are synthesized mostly using petroleum-derived feedstock. With the dwindling petroleum resources [3,4], there is a growing interest to explore alternative raw materials from renewable resources to make bio-based adhesives [5-8].

Lignin is a natural polymer with a three-dimensional network structure that consists of p-hydroxyphenyl propane, guaiacyl propane, and syringyl propane units (Figure 1). The three units are connected through $\mathrm{C}-\mathrm{C}$ and $\mathrm{C}-\mathrm{O}-\mathrm{C}[9,10]$ bonds. Furthermore, lignin is one of the most abundant organic polymeric materials on earth, only second to cellulose. Commercial lignin is mainly obtained from waste liquor in the pulping industry or as a by-product of bio-ethanol production [11,12]. 
<smiles>Oc1ccc(C(F)(F)F)cc1</smiles>

(a)

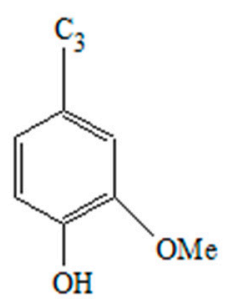

(b)

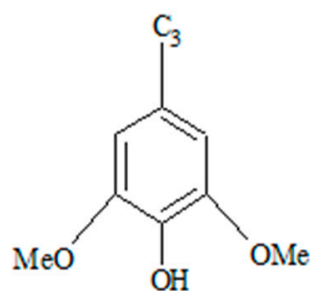

(c)

Figure 1. Three kinds of phenyl propane monomer units of lignin, including (a) p-hydroxyphenyl propane $(\mathrm{H})$; (b) guaiacyl propane $(\mathrm{G})$, and (c) syringyl propane $(\mathrm{S})$.

It has been estimated that the lignin disposal as waste from the global forest industry has increased to 2000 million tons annually in recent years, with wheat straw alkali lignin accounting for $32 \%$ of the total amount. Only less than $2 \%$ of the lignin is reused as organic materials [13]. Most lignin from the forest industry is either burned or directly disposed of in the form of liquid waste [14]. Lignin consists of functional groups exhibiting similar properties to phenol, therefore it is considered the most promising substitute for phenol targeting adhesive applications $[15,16]$. However, lignin is a large molecular weight polymer with a complex structure [17] which has low reactivity towards formaldehyde. In order to enhance the reactivity, many efforts were made to modify lignin, for example, by methylolation, demethylation, and phenolation [16,18-20]. Among these modifications, demethylation has been shown to be an effective method to increase the reactivity of lignin. It has been reported that demethylation of Kraft lignin using sulfur at $225-235^{\circ} \mathrm{C}$ under high pressure enhanced lignin reactivity in phenol formaldehyde adhesives [21]. Later, Wu and Zhang [22] demethylated wheat straw soda lignin using a similar method for preparing lignin-based phenolic formaldehyde adhesives.

Meanwhile, Lewis acids have been successfully applied in demethylation of methoxyl groups in small molecules. Lignin has many methoxyl groups and it has been shown that lignin can also be demethylated using a Lewis acid [23,24]. Furthermore, Chung and Washburn [25] reported demethylation of softwood kraft lignin (SKL) by hydrobromic acid and phase transfer catalyst hexadecyltri- $n$-butylphosphonium bromide (TBHDPB) in a $\mathrm{H}_{2} \mathrm{O}-\mathrm{DMF}$ mixture. The hydroxyl group in SKL increased by $28 \%$ and the demethylated SKL was more reactive than the unmodified SKL when used for polyurethane preparation. Moreover, Ferhan et al. [26] investigated the demethylation of SKL by using in-situ generated hydro-iodic acid, and concluded that the total hydroxyl number of D-SKL increased by $60 \%$ as measured by ${ }^{31} \mathrm{P}$ NMR. So far, there have been few reports on the demethylation of wheat straw alkali lignin (WSAL) by using Lewis acid generated in-situ. WSAL has a higher molecular weight and a higher content of syringl propane units compared with SKL. One important consideration is that WSAL constitutes the majority share of the lignin productions in China. It is valuable to investigate demethylation of WSAL for application in phenol formaldehyde adhesives [27,28].

In this study, WSAL was demethylated by using iodocyclohexane (ICH), and the modification efficacy was evaluated with a Fourier Transform Infrared Spectroscopy (FTIR) semi-quantitative method. The demethylated WSAL was characterized by FTIR, ${ }^{1} \mathrm{H}$ NMR, and Gel Permeation Chromatography (GPC) respectively. The hydroxyl group content was quantified by a titration method. Finally, the demethylated WSAL was used to prepare lignin-based phenol formaldehyde adhesives (D-LPF).

\section{Materials and Methods}

\subsection{Materials}

Wheat straw alkali lignin (WSAL) (hydroxyl group content: $6.65 \mathrm{wt} \%, M_{\mathrm{W}}: 6000 \mathrm{~g} / \mathrm{mol}$, polydispersity index: 1.3, density: $1.30 \mathrm{~g} / \mathrm{cm}^{3}$ ) was purchased from Shandong Quanlin Paper Co., 
Ltd., Gaotang, China. N,N-dimethyl formamide, dichloromethane and ethyl ether (AR grade) were purchased from Strong Functional Chemical Co., Ltd., Changshu, China. Iodocyclohexane was purchased from Tokyo Chemical Plant Type Club (Tokyo, Japan). Formaldehyde solution (37 wt \%), phenol and sodium hydroxide $(\mathrm{NaOH})$ were of analytical grade and purchased from Medicine Group Chemical Reagent Co., Ltd., Shanghai, China. All chemicals were used without further purification.

\subsection{Demethylation of WSAL}

Demethylation of WSAL was carried out as follows (Scheme 1): WSAL, $N, N$-dimethyl formamide (DMF) and iodocyclohexane were charged into a $50 \mathrm{~mL}$ three-neck round bottom flask equipped with a reflux condenser, a magnetic stirrer, and a thermometer. The mixture was stirred and heated to $145^{\circ} \mathrm{C}$, and was kept under a nitrogen atmosphere for $3 \mathrm{~h}$. The mixture was then cooled down to room temperature to terminate the reaction and diluted with a proper amount of dichloromethane. Subsequently, the solvent in the mixture was evaporated under vacuum to obtain the crude product, which was washed twice with $100 \mathrm{~mL}$ deionized water each time. The heterogeneous mixture in water was centrifuged at $5000 \mathrm{rpm}$. The precipitate was dried to a constant weight in a vacuum oven at $80^{\circ} \mathrm{C}$ and stored in a desiccator for further characterization.

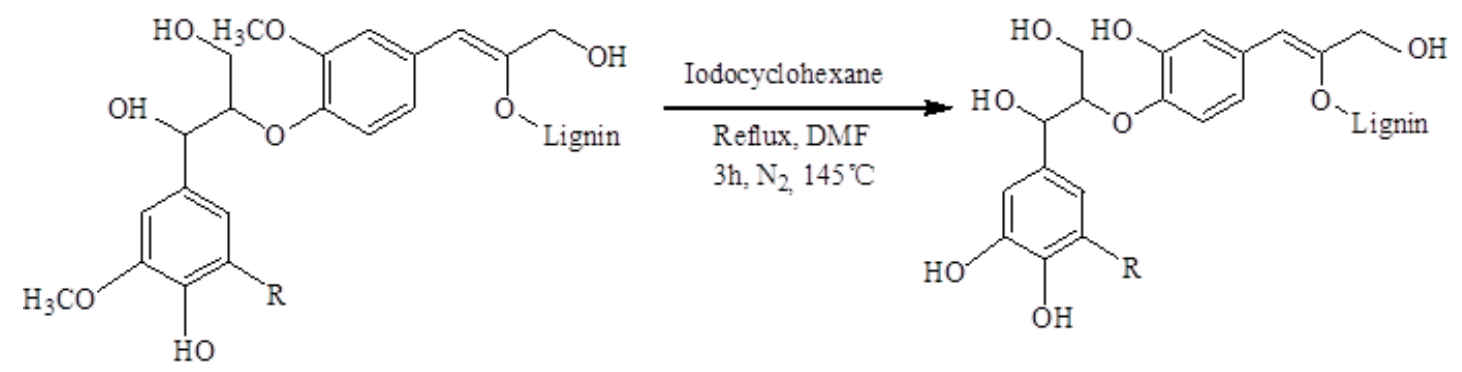

Scheme 1. Demethylation route of WSAL ( $\mathrm{R}$ represents $\mathrm{H}, \mathrm{OH}$ or $-\mathrm{OCH}_{3}$ ). (demethylation was carried out with 10; 1 molar ratio of ICH to lignin at $145^{\circ} \mathrm{C}$ for $3 \mathrm{~h}$ with $4 \mathrm{~mL}$ DMF under nitrogen atmosphere).

\subsection{Preparation of Adhesives}

Phenol formaldehyde (PF) and lignin phenol formaldehyde(LPF) adhesives were prepared in a $100 \mathrm{~mL}$ four-neck round bottom flask equipped with a stirrer, a reflux condenser and a thermometer.

\subsubsection{Preparation of PF Adhesive}

$\mathrm{PF}$ adhesive was prepared according to [29]. Firstly, $0.22 \mathrm{~g} \mathrm{NaOH}, 1.20 \mathrm{~g}$ phenol, and $0.90 \mathrm{~g}$ distilled water were added into a flask, stirred and heated up to $50{ }^{\circ} \mathrm{C}$ for $10 \mathrm{~min}$. Subsequently, $2.03 \mathrm{~g}$ formaldehyde was added dropwise in $5 \mathrm{~min}$. Finally, the mixture was then heated at $90^{\circ} \mathrm{C}$ for $3.5 \mathrm{~h}$.

\subsubsection{Preparation of LPF or D-LPF Adhesive}

LPF adhesives were prepared in two steps: the first step was similar to the preparation of PF adhesives as described above, in which $40 \%$ of phenol was added, and the reaction continued for $1.5 \mathrm{~h}$; Secondly, D-WSAL or WSAL with the substitution of $60 \mathrm{wt} \%$ of phenol, was added to the mixture, and the reaction was kept for $2 \mathrm{~h}$.

\subsection{Preparation of Plywood}

The PF, D-LPF, and LPF adhesives synthesized above were used to prepare lap shear specimens for bonding tests according to the procedure specified by the Chinese National Standard (GB/T 14732-2006 type I plywood). Standard single-layer pine veneers (100 $\mathrm{mm} \times 25 \mathrm{~mm} \times 4.0 \mathrm{~mm}$ ) were dried to $5 \mathrm{wt} \%$ moisture content and coated with $125 \mathrm{~g} / \mathrm{m}^{2}$ adhesive to obtain the two-layer bonded specimens. Specimens with two layers of pine veneers coated with one layer of adhesive were pressed 
at $150{ }^{\circ} \mathrm{C}$ under a pressure of $1.0 \mathrm{MPa}$ for $6 \mathrm{~min}$. The bonded wood samples were kept indoors for $24 \mathrm{~h}$ before the lap-shear measurement (Figure 2).

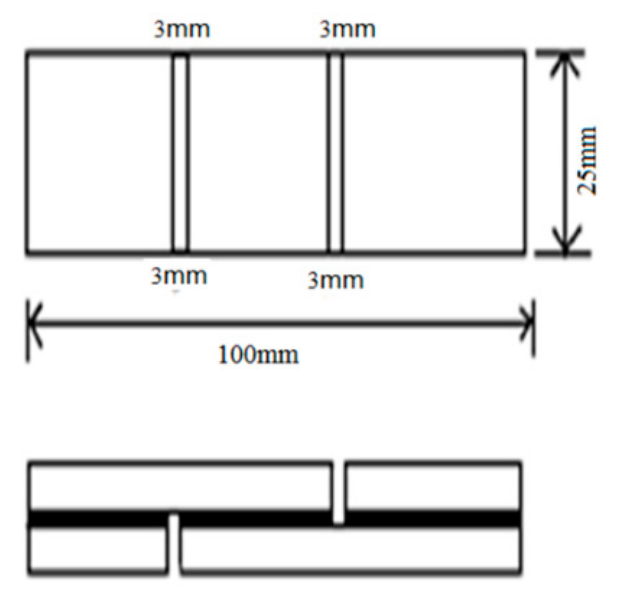

Figure 2. Sample schematic for lap-shear testing $(100 \mathrm{~mm} \times 25 \mathrm{~mm} \times 4.0 \mathrm{~mm})$, with two layers of pine veneers coated with one layer of adhesive.

\subsection{Characterization}

In this study, acetylation of D-WSAL and WSAL was carried out according to the published procedure [30] to improve the accuracy of the FTIR analysis and the degree of dissolution of the samples in solvents for ${ }^{1} \mathrm{H}$ NMR and GPC analysis.

\subsubsection{Fourier Transform Infrared Spectroscopy (FTIR)}

The Avatar370 type Fourier infrared spectrometer (Nicolet Co., Ltd., Madison, WI, USA) was used for the experiments. The testing samples were prepared by grinding a mixture of $2 \mathrm{mg}$ WSAL or D-WSAL and $200 \mathrm{mg} \mathrm{KBr}$ before pressing at $10 \mathrm{MPa}$ for $3 \mathrm{~min}$. The scanning range was $4000-400 \mathrm{~cm}^{-1}$ and the resolution ratio was $4 \mathrm{~cm}^{-1}$.

\subsubsection{Nuclear Magnetic Resonance Spectroscopy (NMR)}

The NMR spectra were recorded on a DRX-400 spectrometer (Bruker Co., Ltd., Fällanden, Switzerland) using DMSO- $\mathrm{d}_{6}$ as the solvent, and the acetylated samples were characterized by $400 \mathrm{M}$ AVANCE type NMR (Bruker Co., Ltd.)

\subsubsection{Average Molecular Weight Determination by Gel Permeation Chromatography (GPC)}

The average molecular weight of acetylated D-WSAL and its distribution were determined with a Waters 1515 gel permeation chromatography (GPC, Waters, Milford, MA, USA) and the device was equipped with a refractive index detector using HR1, HR3, and HR4 columns with molecular weights in the range of 100-500,000 g/mol, calibrated with polystyrene (PS) standard samples.

\subsubsection{Quantification of Hydroxyl Groups}

The total hydroxyl groups of WSAL and D-WSAL were quantified by using a standard phthalation procedure as reported previously [31]. The principle is based on the reaction between the phthalation reagent and the lignin sample to create formic acid which was back-titrated with $1 \mathrm{~mol} / \mathrm{L} \mathrm{NaOH}$ standard solution to the equivalence point. The hydroxyl value was calculated according to the following Equation (1):

$$
\operatorname{Hydroxyl} \text { Value }(\mathrm{mmol} / \mathrm{g})=\frac{\left(V_{\mathrm{A}}-V_{\mathrm{B}}\right) \times N}{W}
$$


where $V_{\mathrm{A}}$ is the volume of $\mathrm{NaOH}$ standard solution consumed to titrate the blank solution, $\mathrm{mL} ; V_{\mathrm{B}}$ is the volume of $\mathrm{NaOH}$ solution used to titrate the sample solution, $\mathrm{mL} ; \mathrm{N}$ is the normality of the $\mathrm{NaOH}$ solution, $\mathrm{mol} / \mathrm{L}$; and $W$ is the weight of the sample, $\mathrm{g}$.

\subsubsection{Properties of the Adhesives}

The adhesive's properties, including solids content, free phenol content, and free formaldehyde content, were determined according to the Chinese National Standards (GB/T 14074-2006). The solids content was measured by weighing $1 \mathrm{~g}$ of sample prior to drying to a constant weight at $120{ }^{\circ} \mathrm{C}$, and then the percentage ratio of the weight of the dried sample to that of the initial sample was namely the solids content. The free phenol in the adhesive was distilled out by steam distillation, and the free phenol content was determined by means of titration with a saturated bromine aqueous solution. The free formaldehyde content was tested using hydroxylamine hydrochloride, and then the free formaldehyde content was titrated with sodium hydroxide solution.

The gel time was measured by charging $1 \mathrm{~g}$ of adhesive into a $12 \mathrm{~mm}$-diameter test tube, and heating the test tube at $150{ }^{\circ} \mathrm{C}$ in an oil bath. Gel time was defined as the time period from placing the test tube into the oil bath to the initial gelation of adhesive.

\subsubsection{Bonding Strength of Lap-Shear Specimens}

Both dry bonding strength and wet bonding strength of the lap-shear samples were tested according to the procedures specified by the Chinese National Standards (GB/T 14074-2006). An electronic universal testing machine (Shanghai Yi Huan Instrument Technology Co., Ltd., Shanghai, China) and a plate curing instrument (Shanghai Machinery Factory Co., Ltd., Shanghai, China) were used in these experiments. All the bonded lap-shear samples were handled in four steps before testing the wet bonding strength as follows: (1) Immersing in boiling water for $4 \mathrm{~h}$; (2) drying at $63^{\circ} \mathrm{C}$ for $20 \mathrm{~h}$; (3) immersing in boiling water for $4 \mathrm{~h}$; (4) cooling for $10 \mathrm{~min}$. The tensile strength of the specimens was measured with an electronic universal testing machine at a constant loading speed of $10 \mathrm{MPa} / \mathrm{min}$. The maximum load was recorded to $10 \mathrm{~N}$ accuracy. Two samples of each lap-shear specimens were tested for wet bonding strength.

\section{Results and Discussion}

\subsection{Optimization of the Demethylation Process}

FTIR is an effective tool to characterize the specific structural groups of polymer materials. Furthermore, the FTIR semi-quantitative method has been used to characterize the relative content of specific groups, in which the phenyl group's skeleton vibration peak at $1503 \mathrm{~cm}^{-1}$ was selected as the reference for calculating the relative values of other groups by area ratios of the peaks [32]. In order to optimize the demethylation process, the influence of various factors on the demethylation reaction was investigated by using the FTIR semi-quantitative method. The factors reported here include ICH dosage based on lignin amount, reaction time, reaction temperature, and solvent types.

\subsubsection{Iodocyclohexane Dosage}

Five levels of iodocyclohexane (ICH) to lignin molar ratios ranged from 5:1 to 15:1 (mol/ $\mathrm{mol}$ ) were used in this set of experiments while keeping the other factors fixed according to literature values and past experiences. Temperature was set at $145^{\circ} \mathrm{C}$ and reaction time was fixed at $3 \mathrm{~h}$ while the volume of the solvents was $4 \mathrm{~mL}$. The synthesized D-WSAL and WSAL were characterized by FTIR and analyzed with the semi-quantitative method (Figure 3, Table 1). The results showed that with an increase in the molar ratio of ICH versus lignin, the relative values of the methoxyl group at $1459 \mathrm{~cm}^{-1}$ exhibited a decreasing trend from 0.82 to 0.17 at a molar ratio of 12:1, and then leveled off. Meanwhile, the relative values of phenol hydroxyl at $1200 \mathrm{~cm}^{-1}$ increased from 1.01 to 11.9 at a molar ratio of 12:1, and then decreased at a higher molar ratio. It seems that overdosed ICH inhibited the demethylation reaction. 
Furthermore, when the molar ratio was less than 10:1, it resulted in a mixture of mono-demethylated and bis-demethylated products, inconsistent with previous reports [23]. Therefore, the molar ratio of 12:1 was chosen for the subsequent demethylation of WSAL.

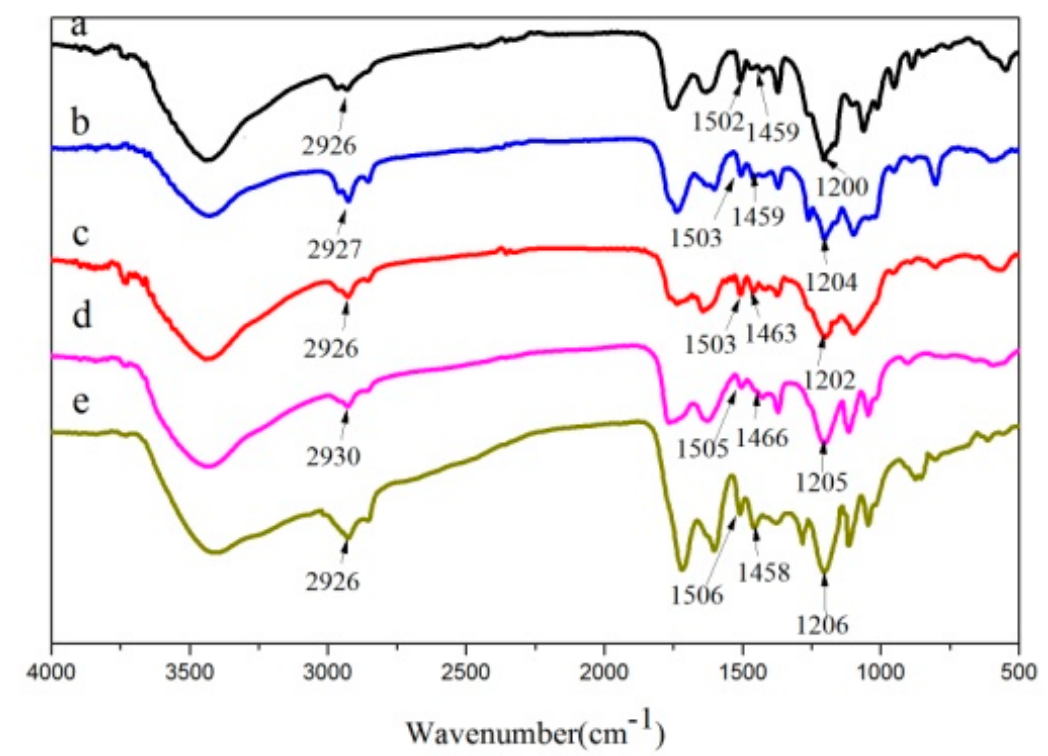

Figure 3. FTIR spectra of acetylated WSAL and D-WSAL with 0 (a), 5:1 (b), 10:1 (c), 12:1 (d) and 15:1 (e) molar ratio of $\mathrm{ICH}$ to lignin, prepared at $145^{\circ} \mathrm{C}$ for $3 \mathrm{~h}$ with $4 \mathrm{~mL}$ DMF under nitrogen atmosphere.

Table 1. Results of FTIR semi-quantitative analysis of the relative values of some functional groups of WSAL and D-WSAL calculated with the phenyl group's skeleton vibration peak at $1503 \mathrm{~cm}^{-1}$ as the reference.

\begin{tabular}{ccccc}
\hline \multirow{2}{*}{ ICH/lignin (mol/mol) } & \multicolumn{3}{c}{ Relative values vs. reference peak } \\
\cline { 3 - 5 } & $\begin{array}{c}\text { C-H stretching } \\
\text { vibration of } \\
-\mathbf{C H}_{3} \text { and }-\mathbf{C H}_{2}\end{array}$ & $\begin{array}{c}\text { C-O deformation } \\
\text { vibration of } \\
\mathbf{C H}_{3}-\mathrm{O}-\end{array}$ & $\begin{array}{c}\text { C-O stretching } \\
\text { vibration of Ar-OH }\end{array}$ \\
\hline \multirow{2}{*}{$0: 1$} & peak area ratio & $\mathrm{A} 2,926 / \mathrm{A} 1,506$ & $\mathrm{~A} 1,457 / \mathrm{A} 1,506$ & $\mathrm{~A} 1,200 / \mathrm{A} 1,506$ \\
& relative value & 1.02 & 0.82 & 1.01 \\
\hline \multirow{2}{*}{$5: 1$} & peak area ratio & $\mathrm{A} 2,927 / \mathrm{A} 1,509$ & $\mathrm{~A} 1,462 / \mathrm{A} 1,509$ & $\mathrm{~A} 1,202 / \mathrm{A} 1,509$ \\
& relative value & 1.34 & 0.45 & 2.92 \\
\hline \multirow{2}{*}{$10: 1$} & peak area ratio & $\mathrm{A} 2,926 / \mathrm{A} 1,506$ & $\mathrm{~A} 1,459 / \mathrm{A} 1,506$ & $\mathrm{~A} 1,204 / \mathrm{A} 1,506$ \\
& relative value & 2.62 & 0.25 & 7.21 \\
\hline \multirow{2}{*}{$12: 1$} & peak area ratio & $\mathrm{A} 2,930 / \mathrm{A} 1,505$ & $\mathrm{~A} 1,460 / \mathrm{A} 1,505$ & $\mathrm{~A} 1,205 / \mathrm{A} 1,505$ \\
& relative value & 3.41 & 0.17 & 11.90 \\
\hline \multirow{2}{*}{$15: 1$} & peak area ratio & $\mathrm{A} 2,926 / \mathrm{A} 1,506$ & $\mathrm{~A} 1,459 / \mathrm{A} 1,506$ & $\mathrm{~A} 1,200 / \mathrm{A} 1,508$ \\
& relative value & 5.70 & 0.19 & 10.31 \\
\hline
\end{tabular}

\subsubsection{Effect of Solvent Amount}

In order to investigate the effect of solvent amount on the demethylation reaction, three DMF to lignin mass ratios ranging from 11.9:1 to 26.1:1 (w/w) were used respectively in this set of experiments with an iodocyclohexane to lignin molar ratio at 12:1 $(\mathrm{mol} / \mathrm{mol})$ and the other reaction conditions kept the same as above. The synthesized D-WSALs were characterized and analyzed (Figure 4 and Table 2). The relative values of methoxyl group at $1459 \mathrm{~cm}^{-1}$ reached a minimum of 0.17 when the solvent dosage was $4 \mathrm{~mL}$, while at the same time the relative value of phenol hydroxyl on D-WSAL at $1200 \mathrm{~cm}^{-1}$ reached a maximum 11.90. Therefore, it can be inferred that the amount of solvent 
is important for the demethylation reaction. A proper amount of solvent would result in effective reactions based on optimum contacts or collisions among different reagents [33]. The results indicated that a mass ratio of 19.0:1 $(w / w)$ was the optimum level to be used, which was in agreement with past work [26].

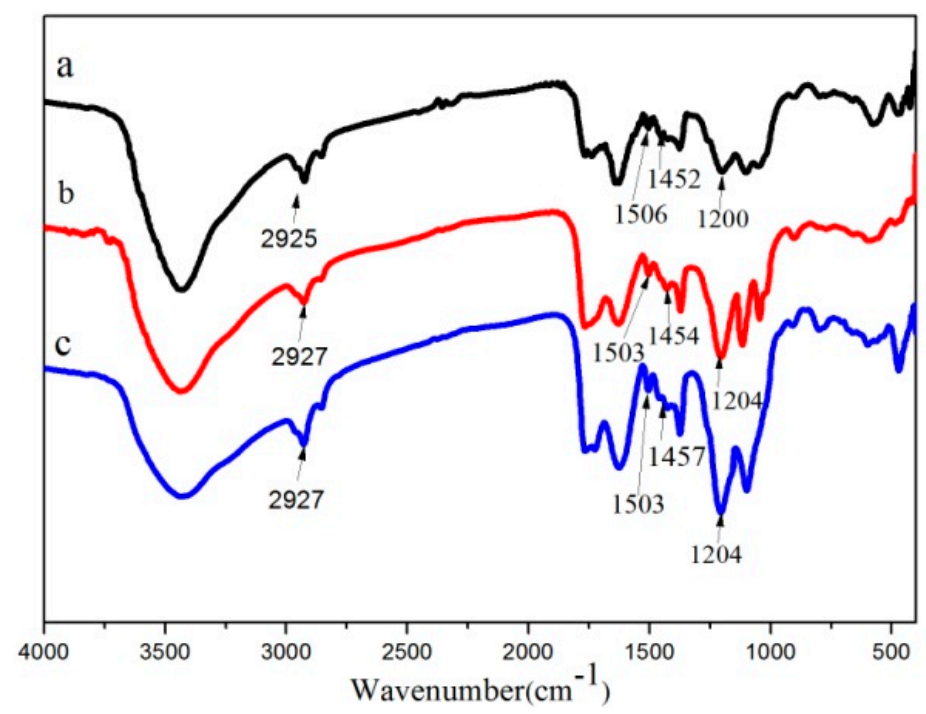

Figure 4. FTIR spectra of D-WSAL prepared with $2.5 \mathrm{~mL}$ (a), $4 \mathrm{~mL}$ (b), and $5.5 \mathrm{~mL}$ (c) DMF with 12:1 molar ratio of ICH to lignin, at $145^{\circ} \mathrm{C}$ for $3 \mathrm{~h}$ under nitrogen atmosphere.

Table 2. Relative values of functional groups on D-WSAL prepared with $2.5 \mathrm{~mL}, 4 \mathrm{~mL}$, and $5.5 \mathrm{~mL}$ DMF with 12:1 molar ratio of $\mathrm{ICH}$ to lignin, at $145^{\circ} \mathrm{C}$ for $3 \mathrm{~h}$ under nitrogen atmosphere. (Phenyl group's skeleton vibration peak at $1503 \mathrm{~cm}^{-1}$ was selected as the reference, the relative values of other groups by area ratios of the peaks were calculated.)

\begin{tabular}{ccccc}
\hline & & \multicolumn{3}{c}{ Relative values based on reference peak } \\
\cline { 3 - 5 } & \multirow{2}{*}{ DMF/lignin $(w / w)$} & $\begin{array}{c}\mathbf{C}-\mathbf{H} \text { stretching } \\
\text { vibration of } \\
\end{array}$ & $\begin{array}{c}\text { C-O deformation } \\
\text { vibration of } \\
\mathbf{C H}_{3} \text { and }-\mathbf{C H}_{\mathbf{2}}\end{array}$ & $\begin{array}{c}\text { C-O stretching } \\
\text { vibration of } \mathbf{A r}-\mathrm{OH}\end{array}$ \\
\hline \multirow{2}{*}{$11.9: 1$} & peak area ratio & $\mathrm{A} 2,925 / \mathrm{A} 1,504$ & $\mathrm{~A} 1,452 / \mathrm{A} 1,504$ & $\mathrm{~A} 1,200 / \mathrm{A} 1,504$ \\
& relative value & 2.68 & 0.27 & 7.52 \\
\hline \multirow{2}{*}{$19.0: 1$} & peak area ratio & $\mathrm{A} 2,927 / \mathrm{A} 1,503$ & $\mathrm{~A} 1,454 / \mathrm{A} 1,503$ & $\mathrm{~A} 1,204 / \mathrm{A} 1,503$ \\
& relative value & 3.41 & 0.17 & 11.90 \\
\hline \multirow{2}{*}{$26.1: 1$} & peak area ratio & $\mathrm{A} 2,927 / \mathrm{A} 1,505$ & $\mathrm{~A} 1,457 / \mathrm{A} 1,505$ & $\mathrm{~A} 1,204 / \mathrm{A} 1,505$ \\
& relative value & 4.02 & 0.24 & 9.83 \\
\hline
\end{tabular}

\subsubsection{Effect of Reaction Temperature}

Three reaction temperatures, specifically 130,145 and $155{ }^{\circ} \mathrm{C}$, were examined for the demethylation of WSAL. The solvent volume was $4 \mathrm{~mL}$, the ICH/lignin molar ratio was 12/1 and other factors were kept the same. The prepared D-WSALs were analyzed the same as in 3.2.2 (Figure 5, Table 3). The lowest relative value of the methoxyl group at $1459 \mathrm{~cm}^{-1}$ was 0.17 at $145^{\circ} \mathrm{C}$, corresponding to the highest relative value (11.9) of phenol hydroxyl group at $1200 \mathrm{~cm}^{-1}$. This could be due to the cross-linking reaction among the hydroxyl groups at $155{ }^{\circ} \mathrm{C}$, leading to a lower relative value (7.63) of phenol hydroxyl groups. However, at $135^{\circ} \mathrm{C}$, the system could not obtain enough thermal energy to overcome the reaction activation energy of the methoxy groups at various positions on WSAL to maximize the demethylation process [34]. Based on these results, $145^{\circ} \mathrm{C}$ was selected as the optimum temperature for the demethylation reaction in this study. 


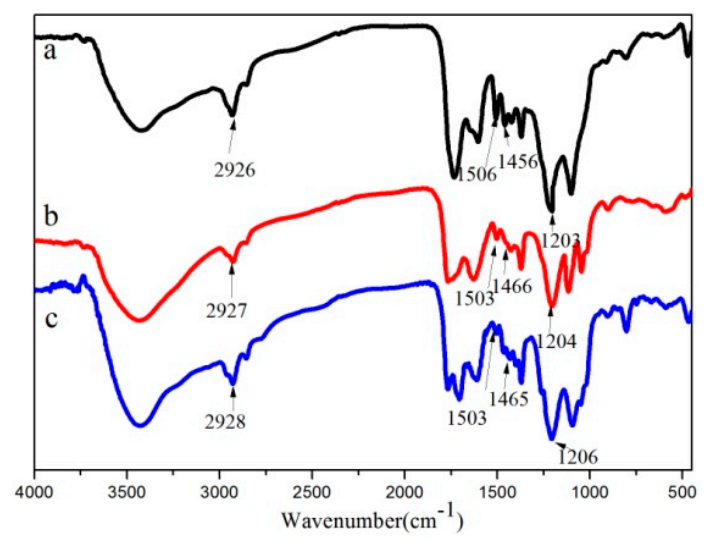

Figure 5. FTIR spectra of D-WSAL synthesized at $135^{\circ} \mathrm{C}(\mathbf{a}), 145^{\circ} \mathrm{C}(\mathbf{b})$, and $155^{\circ} \mathrm{C}$ (c) with $12: 1$ molar ratio of $\mathrm{ICH}$ to lignin for $3 \mathrm{~h}$ with $4 \mathrm{~mL}$ of DMF under nitrogen atmosphere.

Table 3. Relative values of functional groups on D-WSALs synthesized at 135,145 , and $155^{\circ} \mathrm{C}$ (phenyl group's skeleton vibration peak at $1503 \mathrm{~cm}^{-1}$ was selected as the reference, the relative values of other groups by area ratios of the peaks were calculated.)

\begin{tabular}{ccccc}
\hline \multirow{2}{*}{ Temperature $\left({ }^{\circ} \mathbf{C}\right)$} & \multicolumn{3}{c}{ Relative values based on reference peak } \\
\cline { 2 - 5 } & $\begin{array}{c}\mathrm{C}-\mathbf{H} \text { stretching vibration } \\
\text { of }-\mathrm{CH}_{\mathbf{3}} \text { and }-\mathrm{CH}_{\mathbf{2}}\end{array}$ & $\begin{array}{c}\mathrm{C}-\mathbf{O} \text { deformation } \\
\text { vibration of } \mathrm{CH}_{3}-\mathrm{O}-\end{array}$ & $\begin{array}{c}\text { C-O stretching } \\
\text { vibration of } \mathbf{A r}-\mathrm{OH}\end{array}$ \\
\hline \multirow{2}{*}{130} & peak ratio & $\mathrm{A} 2,926 / \mathrm{A} 1,506$ & $\mathrm{~A} 1,456 / \mathrm{A} 1,506$ & $\mathrm{~A} 1,203 / \mathrm{A} 1,506$ \\
& relative value & 2.98 & 0.23 & 7.92 \\
\hline \multirow{2}{*}{145} & peak ratio & $\mathrm{A} 2,927 / \mathrm{A} 1,503$ & $\mathrm{~A} 1,454 / \mathrm{A} 1,503$ & $\mathrm{~A} 1,204 / \mathrm{A} 1,503$ \\
& relative value & 3.41 & 0.17 & 11.90 \\
\hline \multirow{2}{*}{155} & peak ratio & $\mathrm{A} 2,928 / \mathrm{A} 1,503$ & $\mathrm{~A} 1,465 / \mathrm{A} 1,503$ & $\mathrm{~A} 1,206 / \mathrm{A} 1,503$ \\
& relative value & 4.11 & 0.22 & 7.63 \\
\hline
\end{tabular}

\subsubsection{Effect of Reaction Time}

In order to investigate the effect of reaction time on the demethylation of WSAL, the reaction was carried out for $2-7 \mathrm{~h}$ at the reaction temperature $145^{\circ} \mathrm{C}$ with the other reaction factors kept constant. The synthesized D-WSALs were analyzed and results are shown in (Figure 6, Table 4). The relative values of the methoxyl group at $1459 \mathrm{~cm}^{-1}$ changed little up to $7 \mathrm{~h}$ reaction time and the same was true for the phenol hydroxyl groups at $1204 \mathrm{~cm}^{-1}$. However, the maximum relative value of phenol hydroxyl group was 11.90 which was reached after $3 \mathrm{~h}$ of reaction. Therefore $3 \mathrm{~h}$ was chosen as the optimum demethylation time for WSAL. Too long a reaction time could lead to more side reactions, such as cross-linking among the hydroxyl groups [26].

Table 4. Relative values of functional groups on D-WSALs under nitrogen atmosphere for 7, 5, 3, and $2 \mathrm{~h}$ (phenyl group's skeleton vibration peak at $1503 \mathrm{~cm}^{-1}$ was selected as the reference, the relative values of other groups by area ratios of the peaks were calculated).

\begin{tabular}{ccccc}
\hline & & \multicolumn{3}{c}{ Relative values based on reference peak } \\
\cline { 3 - 5 } & Time (h) & $\begin{array}{c}\mathrm{C}-\mathbf{H} \text { stretching vibration } \\
\text { of }-\mathrm{CH}_{3} \text { and }-\mathrm{CH}_{2}\end{array}$ & $\begin{array}{c}\mathrm{C}-\mathbf{O} \text { deformation } \\
\text { vibration of } \mathrm{CH}_{3}-\mathbf{O}-\end{array}$ & $\begin{array}{c}\text { C-O stretching } \\
\text { vibration of } \mathbf{A r}-\mathbf{O H}\end{array}$ \\
\hline \multirow{2}{*}{2} & peak ratio & $\mathrm{A} 2,927 / \mathrm{A} 1,502$ & $\mathrm{~A} 1,458 / \mathrm{A} 1,502$ & $\mathrm{~A} 1,204 / \mathrm{A} 1,502$ \\
& relative value & 2.15 & 0.18 & 11.00 \\
\hline \multirow{2}{*}{3} & peak ratio & $\mathrm{A} 2,927 / \mathrm{A} 1,503$ & $\mathrm{~A} 1,454 / \mathrm{A} 1,503$ & $\mathrm{~A} 1,204 / \mathrm{A} 1,503$ \\
& relative value & 3.41 & 0.17 & 11.90 \\
\hline \multirow{2}{*}{5} & peak ratio & $\mathrm{A} 2,936 / \mathrm{A} 1,506$ & $\mathrm{~A} 1,456 / \mathrm{A} 1,506$ & $\mathrm{~A} 1,204 / \mathrm{A} 1,506$ \\
& relative value & 4.06 & 0.17 & 11.77 \\
\hline \multirow{2}{*}{7} & peak ratio & $\mathrm{A} 2,926 / \mathrm{A} 1,506$ & $\mathrm{~A} 1,456 / \mathrm{A} 1,506$ & $\mathrm{~A} 1,203 / \mathrm{A} 1,506$ \\
& relative value & 5.70 & 0.12 & 10.31 \\
\hline
\end{tabular}




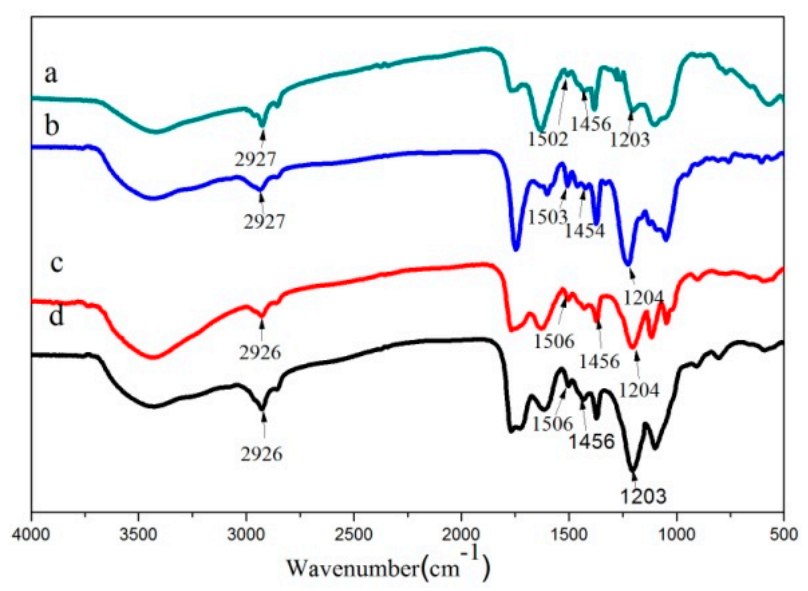

Figure 6. FTIR spectra of WSAL prepared for $7 \mathrm{~h} \mathrm{(a),} 5 \mathrm{~h}(\mathbf{b}), 3 \mathrm{~h} \mathrm{(c)}$, and $2 \mathrm{~h}(\mathbf{d})$ with 12:1 molar ratio of $\mathrm{ICH}$ to lignin with $4 \mathrm{~mL} \mathrm{DMF}$ at $145^{\circ} \mathrm{C}$ under nitrogen atmosphere.

\subsection{Characterization of Demethylated Lignin}

D-WSAL prepared under the optimum demethylation condition, (reaction time of $3 \mathrm{~h}$, reaction temperature at $145{ }^{\circ} \mathrm{C}$, molar ratio of $\mathrm{ICH}$ to lignin at 12:1 and solvent dosage of $4 \mathrm{~mL}$ ), was characterized by FTIR, ${ }^{1} \mathrm{H}$ NMR, and GPC, respectively.

The characteristic peaks of WSAL and D-WSAL obtained from FTIR spectra are shown in Figure 7, and the characteristic peak assignments are listed in Table 5. The absorption peaks at 1372, 1264 and $843 \mathrm{~cm}^{-1}$ showed WSAL as a typical herbaceous lignin [35]. The main difference between D-WSAL and WSAL was the peak area of phenolic hydroxyl groups (higher for D-WSAL) and methoxyl groups (reduced for D-WSAL), which is consistent with previous demethylation studies [36,37]. The FTIR semi-quantitative method was used to characterize the relative content of specific groups. The content of phenolic hydroxyl groups in D-WSAL increased from 1.01 to 11.90 for WSAL, while the methoxyl groups decreased from 0.82 to 0.17 for WSAL. The relative value of phenolic hydroxyl groups was increased by 10.89 , which was higher than that of the methoxy group which decreased by 0.65 . This may be due to part cleavage of ether bonds during the demethylation process [18]. The results showed that the WSAL was demethylated successfully and more efficiently than in other reported methods [21,25]. The methods reported in the past, employed demethylation processes with harsher conditions and had a lower yield of phenolic hydroxyl groups.

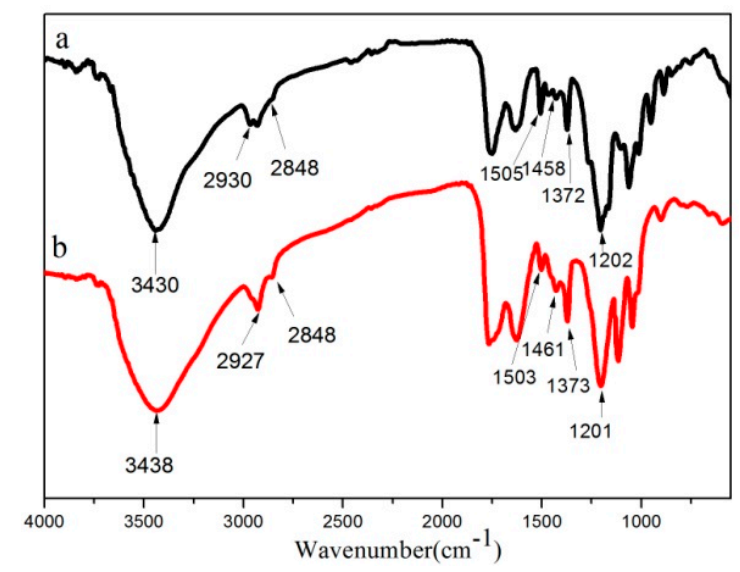

Figure 7. FTIR spectra of WSAL (a) and D-WSAL (b) prepared under the optimum demethylation condition: 12:1 molar ratio of $\mathrm{ICH}$ to lignin, $145{ }^{\circ} \mathrm{C}, 4 \mathrm{~mL}$ DMF, $3 \mathrm{~h}$ reaction time under nitrogen atmosphere. 
Table 5. Assignments of characteristic absorption peaks from the FTIR spectra of WSAL and D-WSAL.

\begin{tabular}{|c|c|c|}
\hline $\begin{array}{l}\text { WSAL band } \\
\text { position }\left(\mathrm{cm}^{-1}\right)\end{array}$ & $\begin{array}{l}\text { D-WSAL band } \\
\text { position }\left(\mathrm{cm}^{-1}\right)\end{array}$ & Assignments \\
\hline 3,430 & 3,438 & $\mathrm{O}-\mathrm{H}$ stretching \\
\hline 2,930 & 2,927 & $\mathrm{C}-\mathrm{H}$ stretching of methyl and methylene group \\
\hline 2,848 & 2848 & $\mathrm{C}-\mathrm{H}$ stretching of methoxy group \\
\hline 1,505 & 1,503 & Aromatic skeletal vibration \\
\hline 1,468 & 1,459 & C-O deformation of methoxyl group \\
\hline 1,372 & 1,373 & $\mathrm{C}-\mathrm{O}$ of syringyl $(\mathrm{S})$ ring \\
\hline 1,264 & 1265 & $\mathrm{C}-\mathrm{O}$ of guaiacy $(\mathrm{G})$ ring \\
\hline 1,205 & 1,203 & C-O stretching of phenolic hydroxyl group \\
\hline 843 & 837 & $\mathrm{C}-\mathrm{O}$ of $\mathrm{p}$-hydroxyphenyl $(\mathrm{H})$ propane \\
\hline
\end{tabular}

D-WSAL was further characterized by ${ }^{1} \mathrm{H}$ NMR. D-WSAL and WSAL were acetylated before the measurement to enhance the solubility of the samples in deuterium reagent. From the ${ }^{1} \mathrm{H} N M R$ spectrum, the phenolic hydroxyl group and aliphatic hydroxyl group could be identified (Figure 8, Table 6). The chemical shift 7.80-7.34 ppm was assigned to the aromatic proton of p-hydroxyphenyl $(\mathrm{H})$, and 7.34-6.80 ppm to the aromatic proton of guaiacyl propane $(\mathrm{G})$, as well as 6.80-6.32 ppm to the aromatic proton of syringyl propane (S), which confirmed the herbaceous lignin's structure of WSAL. These results are consistent with the reported result [38]. Furthermore, the percentage of hydrocarbon increased from 9.5 to 23.6, indicating that a large amount of hydrocarbons had been generated from the degradation of lignin. The percentage of methoxyl group decreased from 17.2 to 8.2, and the percentage of phenolic hydroxyl group increased from 5.2 to 16.0. The decrease of the alcohol hydroxyl group from 13.1 to 10.2 was probably due to the condensation reaction of aliphatic hydroxyl groups as reported previously [32].

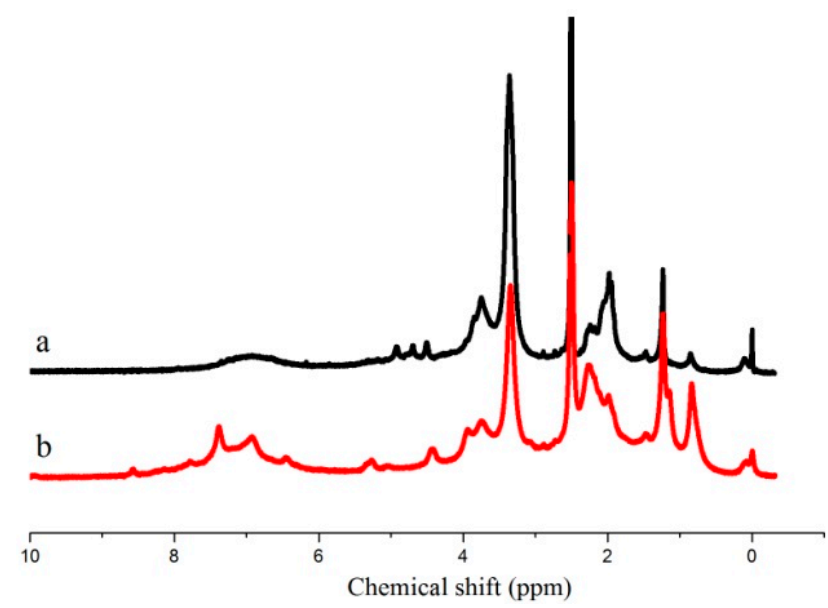

Figure 8. ${ }^{1} \mathrm{H}$ NMR spectra of WSAL (a) and D-WSAL (b) prepared under the optimum demethylation condition: the demethylation process was carried out with 12 molar ratio of ICH to lignin, prepared at $145^{\circ} \mathrm{C}$ with $4 \mathrm{~mL}$ DMF for $3 \mathrm{~h}$ under nitrogen atmosphere.

Table 6. Relative contents of the protons calculated from ${ }^{1} \mathrm{H}$ NMR spectra.

\begin{tabular}{cccc}
\hline \multirow{2}{*}{ Signal (ppm) } & \multicolumn{2}{c}{ H\% } & \multirow{2}{*}{ Assignment } \\
\cline { 2 - 3 } & WSAL & D-WSAL & \\
\hline $1.90-1.21$ & 9.5 & 21.7 & $\mathrm{C}-\mathrm{H}$ \\
$2.17-1.96$ & 13.1 & 10.9 & $\mathrm{R}-\mathrm{OH}$ \\
$2.40-2.17$ & 5.2 & 16.0 & $\mathrm{Ar}-\mathrm{OH}$ \\
$4.00-3.50$ & 17.2 & 8.2 & $\mathrm{CH}_{3}-\mathrm{O}-$ \\
\hline
\end{tabular}


The total hydroxyl content was determined by a titration method. The percentage of phenolic hydroxyl or alcohol hydroxyl groups in the total hydroxyl groups can be calculated according to the integral peak areas from NMR spectra using Equations (2) and (3). The phenolic hydroxyl and alcohol hydroxyl content was respectively calculated $[39,40]$ and given in Table 7.

$$
\begin{aligned}
\mathrm{R}-\mathrm{OH}(\%) & =\frac{\mathrm{R}-\mathrm{OH}_{(\mathrm{H} \%)}}{\mathrm{Ar}-\mathrm{OH}_{(\mathrm{H} \%)}+\mathrm{R}-\mathrm{OH}_{(\mathrm{H} \%)}} \times 100 \\
\mathrm{Ar}-\mathrm{OH}(\%) & =\frac{\mathrm{Ar}-\mathrm{OH}_{(\mathrm{H} \%)}}{\mathrm{Ar}-\mathrm{OH}_{(\mathrm{H} \%)}+\mathrm{R}-\mathrm{OH}_{(\mathrm{H} \%)}} \times 100
\end{aligned}
$$

Table 7. Phenolic hydroxyl and alcohol hydroxyl contents of WSAL or D-WSAL.

\begin{tabular}{cccc}
\hline Sample & Phenol hydroxyl content $(\%)$ & Alcohol hydroxyl content (\%) & Total hydroxyl content (\%) \\
\hline WSAL & 1.89 & 4.74 & 6.63 \\
D-WSAL & 6.10 & 4.16 & 10.26 \\
\hline
\end{tabular}

Molecular weight and polydispersity of D-WSAL were analyzed using GPC (Table 8, Figure 9). The weighted average molecular weight of the original WSAL was $6000 \mathrm{~g} / \mathrm{mol}$ with a polydispersity of 5.3 (provided by the supplier). The results showed that the average molecular weight $\left(\overline{M_{\mathrm{W}}}\right)$ decreased from 6000 to 4033 units and the polydispersity index reduced from 5.1 to 1.0. It indicated that the degradation reaction occurred during the process of lignin demethylation [41], which is in agreement with the results obtained from FTIR semi-quantitative analysis discussed above.

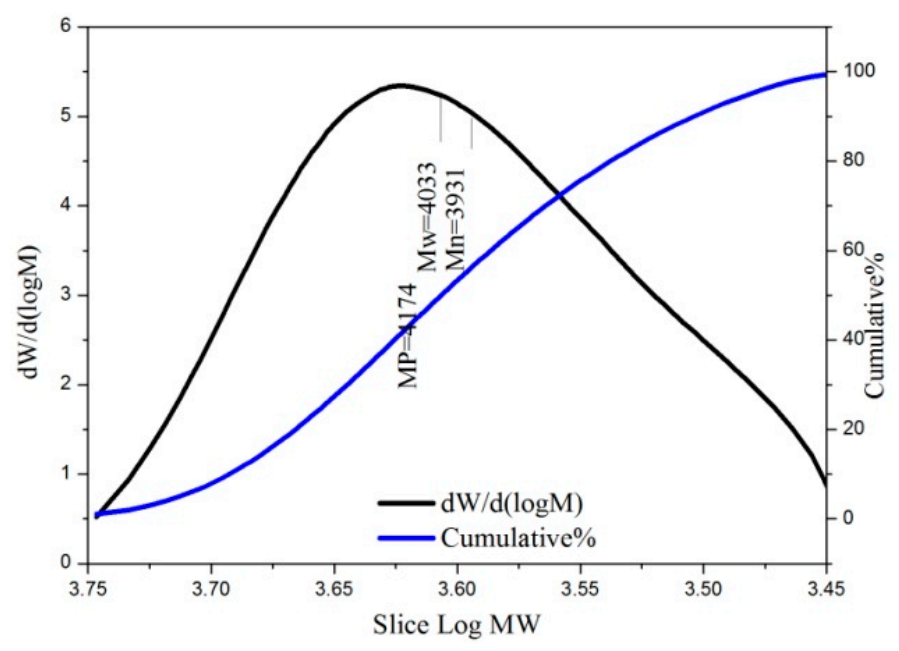

Figure 9. GPC spectrum of D-WSAL prepared under the optimum demethylation condition: 12:1 molar ratio of $\mathrm{ICH}$ to lignin, $145^{\circ} \mathrm{C}, 4 \mathrm{~mL} \mathrm{DMF}$, for $3 \mathrm{~h}$ under nitrogen atmosphere.

Table 8. GPC results of D-WSAL prepared under the optimum demethylation condition (the demethylation process was carried out with 12:1 molar ratio of ICH to lignin, prepared at $145^{\circ} \mathrm{C}$ with $4 \mathrm{~mL}$ DMF for $3 \mathrm{~h}$ under nitrogen atmosphere).

\begin{tabular}{cccc}
\hline Sample & $\overline{M_{\mathbf{n}}}$ & $\overline{M_{\mathbf{W}}}$ & Polydispersity \\
\hline D-WSAL & 3,931 & 4,033 & 1.03 \\
\hline
\end{tabular}

\subsection{Properties of LPF and D-LPF Adhesives}

D-WSAL made by demethylation of WSAL using the optimized process was applied to prepare PF adhesives (D-LPF). In D-LPF synthesis, $60 \mathrm{wt} \%$ of phenol was replaced by D-WSAL. The properties 
of D-LPF adhesives were investigated and compared with adhesives made from WSAL (LPF) as well as PF adhesive without lignin (Table 9). Compared with LPF adhesives, the free formaldehyde content of D-LPF adhesives decreased from $0.65 \%$ to $0.22 \%$, the free phenol content decreased from $2.77 \%$ to $0.92 \%$ and the dry bonding strength increased from 1.13 to $2.28 \mathrm{MPa}$. The wet bonding strength of D-LPF increased from 0.97 MPa for LPF to 2.11 MPa. Furthermore, the gel time of PF, LPF, and D-LPF was 531, 356, and $243 \mathrm{~s}$, respectively. This may be ascribed to a higher reactivity and a lower molecular weight of the demethylated lignin. However, the gel time can also be the result of other factors such as solids content [42]. The $\mathrm{pH}$ values of all adhesives were similar, while the solids content of LPF and D-LPF adhesives were higher than the control PF. However, both the wet bonding strength and dry bonding strength of LPF and D-LPF adhesives were lower than those of the control PF adhesive, and the free formaldehyde content of LPF and D-LPF adhesives increased compared to the control PF adhesive. This may be due to the higher molecular weight and lower reactivity of lignin than phenol [43]. More systematic studies are needed to identify optimum adhesive formulations and processing conditions as well as the impact of the amount of D-WSAL to improve the final performance of D-LPF adhesives.

Table 9. Properties of PF, D-LPF, and LPF adhesives.

\begin{tabular}{cccccccc}
\hline Sample & $\mathbf{p H}$ & $\begin{array}{c}\text { Solids } \\
\text { content (\%) }\end{array}$ & $\begin{array}{c}\text { Free } \\
\text { formaldehyde } \\
\text { content (\%) }\end{array}$ & $\begin{array}{c}\text { Free phenol } \\
\text { content (\%) }\end{array}$ & $\begin{array}{c}\text { Gel time at } \\
\mathbf{1 5 0}{ }^{\circ} \mathbf{C}(\mathbf{s})\end{array}$ & $\begin{array}{c}\text { Dry } \\
\text { bonding } \\
\text { strength } \\
\mathbf{( M P a )}\end{array}$ & $\begin{array}{c}\text { Wet } \\
\text { bonding } \\
\text { strength } \\
\mathbf{( M P a )}\end{array}$ \\
\hline $\mathrm{PF}$ & 10.2 & 40.9 & $0.06 \%$ & 3.01 & 531 & 2.54 & 2.34 \\
$\mathrm{LPF}^{\mathrm{a}}$ & 10.4 & 49.2 & $0.65 \%$ & 2.77 & 356 & 1.13 & 0.97 \\
$\mathrm{D}-\mathrm{LPF}{ }^{\mathrm{b}}$ & 10.4 & 48.7 & $0.22 \%$ & 0.92 & 243 & 2.28 & 2.11 \\
\hline
\end{tabular}

${ }^{a}$ LPF was prepared by WSAL with a phenol hydroxyl content of $1.89 \%{ }^{b}$ D-LPF was prepared by D-WSAL with a phenol hydroxyl content of $6.10 \%$.

\section{Conclusions}

Demethylation of WSAL in-situ by using a Lewis acid to improve the reactivity of WSAL with formaldehyde in adhesive preparation was investigated in this study. The optimum reaction conditions for the demethylation reaction based on the systematic study of the reaction parameters were as follows: reaction temperature of $145^{\circ} \mathrm{C}$, reaction time of $3 \mathrm{~h}$, molar ratio of ICH to lignin of 12:1, and solvent amount of $4 \mathrm{~mL}$. Moreover, the demethylated lignin (D-WSAL) was used to substitute 60 wt \% of phenol in the preparation of lignin containing phenol formaldehyde adhesives (D-LPF). The D-LPF adhesives had a shorter gel time due to the demethylated liginin. Also, the D-LPF contained lower free formaldehyde and free phenol contents, and higher bonding strengths than LPF adhesives with WSAL. Compared with the existing method of demethylation, the reaction condition herein was milder and more economical and environmentally friendly. Therefore, the strategy of using in-situ Lewis acid offers a new promising alternative approach for preparing demethylated lignin with a good potential for application in the phenolic formaldehyde adhesives field.

Acknowledgments: This work was supported by the National Natural Science Foundation of China (51473024), and Changzhou University of Overseas Research \& Training Progamme for middle-aged teachers.

Author Contributions: Jinchun Li and Yan Song conceived and designed the experiments; Zhixin Wang performed the experiments; Yan Song and Ning Yan analyzed the data; Jinchun Li and Rong Zhang contributed reagents/materials/analysis tools; Yan Song wrote the paper.

Conflicts of Interest: The authors declare no conflict of interest.

\section{References}

1. Jin, Y.Q.; Cheng, X.S.; Zheng, Z.B. Preparation and characterization of phenol-formaldehyde adhesives modified with enzymatic hydrolysis lignin. Bioresour. Technol. 2010, 101, 2046-2048. [CrossRef] [PubMed] 
2. Khan, M.A.; Ashraf, S.M.; Malhotra, V.P. Eucalyptus bark lignin substituted phenol formaldehyde adhesives: A study on optimization of reaction parameters and characterization. J. Appl. Polym. Sci. 2004, 92, 3514-3523. [CrossRef]

3. Mourant, D.; Riedl, B.; Rodrigue, D.; Yang, D.Q.; Roy, C. Phenol-formaldehyde-pyrolytic oil resins for wood preservation: A rheological study. J. Appl. Polym. Sci. 2007, 106, 1087-1094. [CrossRef]

4. Hoong, Y.B.; Paridah, M.T.; Luqman, C.A.; Koh, M.P.; Loh, Y.F. Fortification of sulfited tannin from the bark of Acacia mangium with phenol-formaldehyde for use as plywood adhesive. Ind. Crops Prod. 2009, 30, 416-421. [CrossRef]

5. Khan, M.A.; Ashraf, S.M. Development and characterization of a lignin-phenol-formaldehyde wood adhesive using coffee bean shell. J. Adhes. Sci. Technol. 2005, 19, 493-509. [CrossRef]

6. Feng, S.H.; Yuan, Z.S.; Leitch, M. Adhesives formulated from bark bio-crude and phenol formaldehyde resole. Ind. Crops Prod. 2015, 76, 258-268. [CrossRef]

7. Özçifçi, A. Effects of boron compounds on the bonding strength of phenol-formaldehyde and melamine-formaldehyde adhesives to impregnated wood materials. J. Adhes. Sci. Technol. 2006, 20, 1147-1153. [CrossRef]

8. Effendi, A.; Gerhauser, H.; Brindgwater, A.V. Production of renewable phenolic resins by thermochemical conversion of biomass: A review. Renew. Sustain. Energy Rev. 2008, 12, 2092-2116. [CrossRef]

9. Vanholme, R.; Demedts, B.; Morreel, K.; Ralph, J.; Boerjan, W. Lignin biosynthesis and structure. Plant Physiol. 2010, 153, 895-905. [CrossRef] [PubMed]

10. Oliveira, L.; Evtuguin, D.; Cordeiro, N. Structural characterization of stalk lignin from banana plant. Ind. Crops Prod. 2009, 29, 86-95. [CrossRef]

11. Yang, H.P.; Yan, R.; Chen, H.P.; Lee, D.H.; Zheng, C.G. Characteristics of hemicellulose, cellulose and lignin pyrolysis. Fuel 2007, 86, 1781-1788. [CrossRef]

12. Baucher, M.; Monties, B.; Montagu, M.V.; Boerjan, W. Biosynthesis and genetic engineering of lignin. Crit. Rev. Plant Sci. 2010, 17, 125-197. [CrossRef]

13. Ouyang, X.P.; Zhu, G.D.; Huang, X.Z.; Qiu, X.Q. Microwave assisted liquefaction of wheat straw alkali lignin for the production of mono-phenolic compounds. J. Energy Chem. 2015, 24, 72-76. [CrossRef]

14. Buranov, A.U.; Mazza, G. Lignin in straw of herbaceous crops. Ind. Crops Prod. 2008, 28, 237-259. [CrossRef]

15. Ibrahim, M.N.M.; Zakaria, N.; Sipaut, C.S.; Sulaiman, O.; Hashim, R. Chemical and thermal properties of lignin from oil palm biomass as a substitute for phenol in a phenol formaldehyde resin production. Carbohydr. Polym. 2011, 86, 112-119. [CrossRef]

16. Hu, L.H.; Pan, H.; Zhou, Y.; Zhang, M. Methods to improve lignin's reactivity as a phenol substitute and as replacement for other phenolic compounds: A brief review. Bioresources 2011, 6, 3515-3525.

17. Alonso, M.V.; Oliet, M.; Pérez, J.M.; EcheverríA, J.; RodríGuez, F. Determination of curing kinetic parameters of lignin-phenol-formaldehyde resole resins by several dynamic differential scanning calorimetry methods. Thermochim. Acta 2004, 419, 161-167. [CrossRef]

18. Wang, G.; Chen, H. Carbohydrate elimination of alkaline-extracted lignin liquor by steam explosion and its methylolation for substitution of phenolic adhesive. Ind. Crops Prod. 2014, 53, 93-101. [CrossRef]

19. Ibrahim, V.; Mendoza, L.; Mamo, G.; Hatti-Kaul, R. Blue laccase from Galerina s-p.: Properties and potential for Kraft lignin demethylation. Process Biochem. 2011, 46, 379-384. [CrossRef]

20. Liu, G.Y.; Qiu, X.Q.; Xing, D.S. Phenolation modification of wheat straw soda lignin and its utilization in preparation of lignin-based phenolic formaldehyde resins adhesive. J. Chem. Eng. Chin. Univ. 2007, 21, 678-684.

21. An, X.N.; Schroeder, H.A. Demethylated kraft lignin as a substitute for phenol in wood adhesive. Chem. Ind. For. Prod. 1995, 3, 36-42.

22. Wu, S.B.; Zhang, H.Y. Characteristics of demethylated wheat straw soda lignin and its utilization in lignin-based phenolic formaldehyde resins. Cell. Chem. Technol. 2001, 35, 253-262.

23. Zuo, L.; Yao, S.Y. An efficient method for demethylation of aryl methyl ethers. Tetrahedron Lett. 2008, 49, 4054-4056. [CrossRef]

24. Makara, G.M.; Klubek, K.; Anderson, W.K. An efficient synthesis of 5,7-dimethoxy-4-methylphthalide, a key intermediate in the synthesis of mycophenolic acid. J. Org. Chem. 2002, 60, 5717-5718. [CrossRef]

25. Chung, H.Y.; Washburn, N.R. Improved lignin polyurethane properties with lewis acid treatment. ACS Appl. Mater. Interfaces 2012, 4, 2840-2846. [CrossRef] [PubMed] 
26. Ferhan, M.; Yan, N.; Sain, M. A new method for demethylation of lignin from woody biomass using biophysical methods. Chem. Eng. Technol. 2013, 4, 5.

27. Mansouri, N.E.E.; Mail, Q.Y.; Huang, F. Characterization of alkaline lignins for use in phenol-formaldehyde and epoxy resins. Bioresources 2011, 6, 2647-2662.

28. Kabuyah, R.N.T.M.; Dongen, B.E.V.; Bewsher, A.D. Decomposition of lignin in wheat straw in a sand-dune grassland. Soil Biol. Biochem. 2012, 45, 128-131. [CrossRef]

29. Tabarsa, T.S.; Jahanshahi, S.; Ashori, A. Mechanical and physical properties of wheat straw boards bonded with a tannin modified phenol-formaldehyde adhesive. Compos. Part B 2011, 42, 176-180. [CrossRef]

30. Qiu, X.Q.; Li, H.; Deng, Y.H. Acetylation of alkali lignin and preparation of spherical micelles. Acta Polym. Sin. 2014, 11, 1458-1464.

31. Kurimoto, Y.; Doi, S.; Tamura, Y. Species effects on wood-liquefaction in polyhydric alcohols. Holzforschung 1999, 53, 617-622. [CrossRef]

32. Qiu, X.Q.; Yang, D.J.; Zhou, H.F. Study on the activity of the activated alkali lignin by laccase. Acta Polym. Sin. 2013, 2, 232-240.

33. Fang, Z.; Zhou, G.C.; Zheng, S.L. Lithium chloride-catalyzed selective demethylation of aryl methyl ethers under microwave irradiation. J. Mol. Catal. A Chem. 2007, 274, 16-23. [CrossRef]

34. Hu, L.H.; Zhou, Y.H.; Pan, H.; Zhang, M.; Liu, R.J. Study on lignin demethylation and structural characterization of its products. Polym. Bull. 2012, 3, 77-84.

35. Monteil-Rivera, F.; Phuong, M.; Ye, M.; Halasz, A. Isolation and characterization of herbaceous lignin for applications in biomaterials. Ind. Crops Prod. 2013, 41, 356-364. [CrossRef]

36. Kubo, S.; Kadla, J.F. Hydrogen bonding in lignin: A fourier transform infrared model compound study. Biomacromolecules 2005, 6, 2815-2821. [CrossRef] [PubMed]

37. Pandey, K.K. A study of chemical structure of soft and hardwood and wood polymers by FTIR spectroscopy. J. Appl. Polym. Sci. 1999, 71, 1969-1975. [CrossRef]

38. Chen, X.; Yan, N. Novel catalytic systems to convert chitin and lignin into valuable chemicals. Catal. Surv. Asia 2014, 18, 164-176. [CrossRef]

39. Fan, Y.M. Delignification mechanism and chemical reactions in the formic acid pulping process of wheat straw. Ph.D. Thesis, Beijing Forest University, Beijing, China, 2007.

40. Hu, L.H. Study on the preparations and properties of lignin-based phenolic foam thermal insulation materials. Ph.D. Thesis, Chinese Academy of Forestry, Beijing, China, 2012.

41. Sun, Q.N.; Qin, T.F.; Li, G.Y. Chemical groups and structural characterization of brown-rotted pinusmassoniana lignin. Int. J. Polym. Anal. Charact. 2008, 14, 19-33. [CrossRef]

42. Zhao, M.Z.; Jing, J.L.; Zhu, Y.C. Preparation and performance of lignin-phenol-formaldehyde adhesives. Int. J. Adhes. Adhes. 2016, 64, 163-167. [CrossRef]

43. Ghaffar, S.H.; Fan, M. Lignin in straw and its applications as an adhesive. Int. J. Adhes. Adhes. 2014, 48, 92-101. [CrossRef]

(C) 2016 by the authors; licensee MDPI, Basel, Switzerland. This article is an open access article distributed under the terms and conditions of the Creative Commons Attribution (CC-BY) license (http://creativecommons.org/licenses/by/4.0/). 